\section{Marco Trucco}

Received: 29 December 2006

Accepted in revised form: 23 January 2007

Published online: 11 May 2007

\title{
Nummular headache: another case treated with gabapentin
}

Sir,

Nummular headache (NH) is a chronic, mild-to-moderate head pain located in a small circumscribed area of the head in the absence of any lesion of cranial structures, first described by Pareja et al. [1]. It was coded as A13.7.1 in the Appendix of the ICHD-II Classification [2]. It was treated with NSAIDs, analgesics, botulinum toxin [3] and gabapentin (GBP) [4]. In a recent series of three cases [5], various drugs and local nerve blocks brought no relief.

OF, a 26-year-old woman, reported, for about one year previous, a continuous pressure-like pain of mild intensity in a rounded area of 3-4 cm diameter of the left parietal region close to the midline. The pain tended to worsen in intensity during the evening hours, and was accompanied with discomfort and increased sensitivity to light touch within the same area. No nausea, vomiting, photophobia or phonophobia were reported. She had been suffering from mild head trauma for seven years before the onset of pain. She did not take any medication. Neurological examination was unremarkable.

She underwent routine blood tests, EKG and EEG, all without abnormalities. Cerebral angio-MRI with CE was normal except for a cho- lesterol granuloma at the apex of right temporal pyramid. Roentgenogram of cervical spine showed only a minimal scoliosis and cervical hypolordosis.

In accordance with ICHD-II criteria, a diagnosis of $\mathrm{NH}$ was made and treatment with GBP was prescribed, at the initial dose of $300 \mathrm{mg}$, reaching a final dose of $300 \mathrm{mg}$ t.i.d. in two weeks. Full dose was not tolerated because of dizziness and restlessness. At the dose of $600 \mathrm{mg}$ the patient experienced full remission of pain, while local cutaneous hypersensitivity persisted.

She stopped spontaneously GBP after two months, without recurrence of pain until now (three further months of follow-up). In our opinion, this observation adds further evidence to the efficacy of GBP in NH.

M. Trucco (凶) Headache Centre, Department of Neurosciences, Santa Corona Hospital, Via XXV Aprile 38, I-17027 Pietra Ligure, Italy e-mail:

marco.trucco@ospedalesantacorona.it 


\section{References}

1. Pareja JA, Caminero AB, Serra J et al (2002) Numular headache: a coinshaped cephalgia. Neurology 58:1678-1679

2. Headache Classification Subcommittee of the International Headache Society. (2004) The International Classification of Headache Disorders, 2nd edn. Cephalalgia 24[Suppl 1]:1-160
3. Seo MW, Park SH (2005) Botulinum toxin treatment in nummular headache. National Headache Foundation 3rd Annual Headache Research Summit. Cephalalgia 25:991

4. Trucco M, Mainardi F, Perego G, Zanchin G (2006) Nummular headache: first Italian case and therapeutic proposal. Cephalalgia 26:354-356
5. Dach F, Speciali J, Eckeli A et al (2006) Nummular headache: three new cases. Cephalalgia 26:1234-1237 